Referencia para citar este artículo: Castañeda-Lozano, Y. (2017). Family Guy y South Park: Perfiles de los Actuales Estilos de Vida (2013-2015). Revista Latinoamericana de Ciencias Sociales, Niñez y Juventud, 15(1), pp. 71-84.

\title{
Family Guy y South Park: Perfiles de los actuales estilos de vida*
}

\author{
YEBRAIL CASTAÑEDA-LOZANO**
}

Profesor Universidad de La Salle, Colombia.

\section{Artículo recibido en octubre 30 de 2015; artículo aceptado en febrero 24 de 2016 (Eds.)}

- Resumen (descriptivo): Esta reflexión pretende determinar los estilos de vida que modelan los mass media especificamente en South Park y Padre de Familia. Expondré las caracteristicas de estas dos series foráneas, en sus protagonistas, para inferir los estilos de vida y las identidades que se han incorporado en las poblaciones infantiles y juveniles latinoamericanas. Las fases de este escrito están en rastrear la tradición literaria, precisar su historia, elucidar los conceptos de cada programa, colegir los estilos de vida y definir las identidades emergentes. La metodología es diagnosticar cada personaje según sus inclinaciones y obsesiones, delinear estas nociones y proyectarlas en estilos de vida, conforme con las coordenadas sociales y culturales, para configurarlas en identidades que presentaré en las conclusiones.

Palabras clave: Vida cultural (44), estilo de vida (191), medios de comunicación (5), vida cotidiana (136) (Tesauro de Ciencias Sociales de la Unesco).

\section{Family Guy and South Park profiles of current lifestyle}

- Abstract (descriptive): This reflective article seeks to identify lifestyles modeled by the mass media, specifically the South Park and Family Guy television shows. The characteristics of these two series are presented and analyzed, ranging from the shows 'protagonists to the lifestyles and identities that they represent, which Latin American children and youth have adopted and incorporated into their lives. This article traces the literary tradition of these shows, describes their history and the main concepts of each program, identifies the lifestyles that are projected in the shows and defines the identities that are emerging among children and young people in Latin America. The methodology involved a diagnostic of each character, identifying their inclinations and obsessions and projecting these notions into certain lifestyles that they represent, in accordance with social and cultural contexts, in order to establish an approximation of their identities, which is presented in the conclusions.

Key words: Cultural life (44), lifestyle. (191), mass media (5), everyday life (136) (Social Science Unesco Thesaurus).

\section{Family Guy e South Park perfis dos atuais estilos de vida}

- Resumo (descritivo): Esta reflexão tem por objetivo determinar os estilos de vida que moldam os meios de comunicação, especificamente de South Park e Family Guy. As características destas

\footnotetext{
El presente artículo de reflexión es fruto de una parte del desarrollo del objetivo de seleccionar y analizar contenidos y orientaciones didáctico/ metodológicas en los discursos de los profesores, profesoras y estudiantes según la diversidad cultural y religiosa. De la investigación titulada: "Diversidad Cultural y Educación Escolar en Brasil y en Colombia: Implicaciones en profesores y en profesoras". Trabajo Financiado por las Universidades Pontificia de Paraná (Brasil) y Universidad de la Salle (Bogotá-Colombia). Referencia: DEC-265-13. La investigación inició en el mes de febrero de 2013 y finalizada en el mes de diciembre de 2016. La investigación es de naturaleza descriptiva-analítica. Área: Ciencias Sociales. Subárea: Sociología de la religión. Tema específico: Estilos de vida.

** Docente del Programa de la Licenciatura en Educación Religiosa de la Universidad de La Salle. Candidato al Doctorado en Filosofía de la Universidad Santo Tomás. Magíster en Educación de la Universidad Javeriana. Licenciado en Filosofía y Letras y Especialista en Filosofía de la Educación de la Universidad de la Salle. Correo electrónico: ycastaneda@unisalle.edu.co
} 
duas séries estrangeiras serão expostas a partir de seus protagonistas para inferir estilos de vida e identidades, que são incorporados em crianças e jovens latino-americanos. As fases deste trabalho estão em rastrear a tradição literária, identificar sua história, elucidar os conceitos de cada programa, deduzir os estilos de vida e definir identidades emergentes. A metodologia será diagnosticar cada personagem desde suas inclinações e obsessões, delinear essas noções e projetá-las em estilos de vida, de acordo com coordenadas sociais e culturais e defini-los em identidades para ser apresentado nas conclusões.

Palavras chave: A vida cultural (44), estilo de vida (191), meios de comunicação (5), vida cotidiana (136) (Tesauro de Ciências Sociais da Unesco).

\section{-1. Introducción. -2. Series televisivas. -3. Estilos de vida. -4. Lista de referencias.}

\section{Introducción}

La preocupación por los proyectos de vida de los niños, niñas y jóvenes, es un asunto de discusión en los niveles escolares y académicos. Se puede observar que en la literatura escolar sobre este tema se encuentran textos como construyendo su proyecto de vida de Inés Pardo (2005), quien centra el proyecto de vida en la solidez familiar. La cartilla mi proyecto de vida, de Patricia López (2004), enfoca la temática en el conocimiento y autorreconocimiento personal. El libro a cada cual con su misión de Monbourquette (2000), presenta el itinerario de vida en la configuración de la identidad en la misión y en la visión. En las investigaciones doctorales sobre el tema del proyecto de vida encontramos el trabajo de Julio Espinosa (2011), titulado La igualdad de género en la evaluación de la ayuda del desarrollo, que aborda las variantes del desarrollo y de la igualdad de género, susceptible de direccionarse como política pública. La reflexión de José A. Rodríguez (2014), nombrada Aproximación de un modelo teórico de participación social que ofrezca la calidad de vida en el contexto de la educación venezolana. Se piensa el proyecto de vida en un diseño modelable según el espíritu de la calidad de vida, según los referentes de la construcción cultural participativa y con la experiencia de los conocimientos e interpretaciones de la misma realidad. Finalmente, Santiago Penas (2008) con su trabajo Aproximación a los valores y estilos de vida de los jóvenes de 13 y 14 años de la Provincia de Coruña, ubica el camino de vida en la presentación y socialización de los valores en los frentes de la familia, la escuela y el ocio, influenciado este camino por las tecnologías y los medios de comunicación que actualmente están construyendo la noción de estilo de vida.

En este breve recorrido teórico sobre el tema del proyecto de vida, tematizo diferentes nociones de análisis, como son: el conocimiento personal, la configuración de la identidad, las formas vitales, los estilos de vida promovidos por los papeles propios de las familias y de las escuelas. Estos proyectos de vida se acentúan y se desarrollan por los estilos de vida que se presentan como escenarios susceptibles de ser modelados conforme a las variantes de los géneros, la búsqueda de una mejor vida y el diseño de políticas públicas direccionadas por los gobiernos de turno. Alrededor de la noción de proyecto de vida oscilan categorías de caminos, formas, planes, itinerarios, rutas, modos, estilos de vida, entre otras. Estas categorías se encuentran fuertemente influenciadas por las tendencias de los mass media y de las tecnologías de la información y de la comunicación (TIC), que han llevado a conformar las actuales formas vitales de los niños, niñas y jóvenes. La población infantil y juvenil es vulnerable frente a la extensa y variada oferta consumista que promueven los medios de comunicación y las mediaciones tecnológicas y de la información, respecto a las cuales las manifestaciones recurrentes de esta población son: la admiración, la imitación y la representación de sus íconos favoritos. Esas idolatrizaciones de las nuevas generaciones se incorporan en sus existencias sin ningún tipo de crítica o resistencia.

Los estilos de vida de los niños se encuentran perfilados con los personajes de 
los Simpson, Bob Esponja, Cartman, Gokú. Para las niñas, los personajes femeninos más relevantes son: Sherezade, las Superpoderosas y Anna de Frozen. Para los individuos jóvenes de ambos sexos se encuentran los héroes y los superhéroes de Batman, Superman, Capitán América, la Mujer Maravilla, Optimus Prime, los Vengadores, entre otros. La argumentación que expone la población infantil y juvenil latinoamericana sobre el favoritismo por sus personajes o ídolos foráneos, se encuentra en las aventuras que corren con suerte los personajes; en la versatilidad que se manifiesta en las fuerzas y en los poderes de sus héroes; en la velocidad, el enigma y la oscuridad de los íconos televisivos o cinematográficos; en la sensibilidad frente a la bondad amenazada por la maldad, en la estética de sus uniformes o accesorios y en la justicia que imparte cada uno de los superhéroes; en la irreverencia, la crítica y la mofa de algunas figuras de unas de las series animadas como South Park y Padre de Familia.

Los estilos de vida se han establecido por la combinación sincretista y ecléctica de íconos, imágenes y representaciones, constituyendo una plataforma axiológica comprendida por la diversidad de valores, valoraciones y ponderaciones -tanto fragmentarias como totalizantes- sobre las categorías de verdad, responsabilidad, libertad, justicia, emocionalidad, grandiosidad, sublimidad, comicidad, tragicidad, tolerancia, igualdad, solidaridad, amistad, entre otras.

El propósito de este artículo reflexivo se encuentra en identificar los estilos de vida y los valores que se manifiestan en las series de televisión South Park y Padre de Familia. Para describir el propósito de dichas series de televisión haré hincapié en los siguientes desarrollos: la tradición literaria, una breve historia, el concepto que comunica y los estilos de vida que se presentan en cada uno de los personajes de las series. En esta perspectiva, los estilos de vida que se han conformado desde el siglo pasado han estado modelados por los medios de comunicación, que se han ubicado como fines alienantes y no como medios para la humanización, que se han introducido por un profundo mercadocentrismo caracterizado por la creación y la constitución de necesidades no sentidas en la sociedad, por la depredación tecnológica manifestada en la obsolescencia de los dispositivos que simbólicamente se han prologado en las formas de caducidad existencial humana. En la actualidad, las personas han interiorizado estos dinamismos tanto tecnológicos como mass-mediáticos en los estilos de vida, mediante la personificación y la subjetivación de los íconos, que se encuentran de moda en los medios masivos de la comunicación.

Entre los estudios más significativos sobre los mass media se encuentran El fin de los medios de comunicación (Jarvis, 2014), que aborda los mass media según las relaciones, las formas y los modelos, examinando el futuro que les puede deparar. El autor ubica el rol de los medios de comunicación vinculado con las empresas enfocadas al servicio de las necesidades individuales de cada persona. El texto El caos digital y medios comunes. Transformaciones de la comunicación social (González \& Rodríguez, 2014) señala los desafíos, los riesgos y las consecuencias de las actuales transformaciones de la comunicación social, gracias a la creatividad digital, el cambio tecnológico y el progreso económico mediante las metodologías del materialismo dialéctico, la teoría crítica y la economía política de la comunicación. El anuario Análisis de tendencias de información y documentación (Baiget, 2015) aborda las tendencias del ámbito de la informática y la documentación en el contexto de 2012 en el que presenta categorías como las comunidades de aprendizaje, la impartición de cursos de toda índole, el desarrollo del marketing de la información o web sociales, las tecnologías móviles, la tecnología humana, entre otras. Finalmente, los Indicadores de género para medios de comunicación (Unesco, 2014) presenta un marco de indicadores para evaluar la sensibilidad en materia de género en las operaciones y contenidos mediáticos. En este marco, presento los indicadores y los medios de verificación en las materias de balance e igualdad de género con el correspondiente diseño de códigos de ética que busquen dicha armonización. 
Los mass media han marcado las pautas de personificación en las personas con una progresiva consecución imaginativa del prestigio, de la popularidad y del éxito. La subjetivación mediática se muestra con el anhelo de hominización mercantilista, tecnológica y comunicativa que busca forjar la individualidad a su medida. En esta perspectiva se pretende describir y analizar los estilos de vida provenientes de las series de televisión anteriormente mencionadas, con las siguientes preguntas: ¿cómo se crearon?, ¿cuáles eran las intenciones de sus creadores?, y ¿qué estilo de vida pretendían mostrar? Estas inquietudes se responden en un breve recorrido histórico, con la definición conceptual de la serie y con la especificación de los estilos de vida.

Las metodologías para responder a cada una de estas preguntas tienen el siguiente itinerario: con relación a la creación de South Parky Padres de familia señalo los frentes: de los escenarios, la fecha de su origen, el por qué se realizó y el fenómeno azaroso que produjo dichas series televisivas. Con respecto a las intenciones de los autores determino los siguientes referentes: el concepto, y los personajes de cada una de ellas. El concepto se entiende como las oscilaciones permanentes y recurrentes de las tramas que presenta cada uno de los programas. En este análisis abordo los personajes principales y examino su situación socio-económica, cultural, política, religiosa, psicológica, sus coherencias, transformaciones y distorsiones. Elaboro la constitución y categorización de los estilos de vida con el siguiente procedimiento: tomo los análisis sociales anteriores y a partir de estas valoraciones categorizo sus inclinaciones, sus obsesiones y sus preocupaciones. Una vez detalladas estas características proyecto los estilos de vida en las coordenadas culturales, sociales o religiosas. En este artículo desarrollo un ejemplo con Kenny, el niño silencioso de South Park, quien accidentalmente muere al final de los capítulos. Su personalidad enigmática y oculta proyecta el estilo de vida de la ausencia social, de la ocultación comunitaria y el sistemático anonimato, que le anulan las posibilidades de participación en la sociedad. Finalmente, sintetizo los estilos de vida en dos momentos: el primero son las presentaciones de los estilos de vida tradicionales de la sociedad que representan los personajes de las dos series. El segundo son los estilos de vida emergentes que representan dichos personajes, cuya tendencia es realizarse en el futuro. Estudio los estilos de vidas tradicionales y emergentes según la ética, entendida como la reflexión de la moral, en la estética comprendida como la contemplación de lo sublime, y en la política, que es el discernimiento entre el bien particular y el bien general.

\section{Series Televisivas}

Las series de South Park y Padre de Familia se presentan en el formato de dibujos animados. Su paradoja radica en que son observados por los niños, niñas y adolescentes, pero el contenido está dirigido a un público adulto. En los dos programas se muestran unas familias disfuncionales que critican de forma irreverente, ácida y distorsionada los órdenes establecidos por la cultura y la sociedad. Para argumentar el desorden social y el caos mundial, estas dos series utilizan un lenguaje fuerte, sarcástico, irónico, violento y directamente grosero e insultante. Los libros que se refieren a estas dos series se presentan como guías de vida, reflexiones filosóficas y ensayos sociológicos que desnudan una realidad fragmentada, hipócrita y doble-moralista. En estas obras se delinean metafóricamente los estilos de vida con una guía o un guion existencial, para aplicarlos actualmente o proyectarlos hacia el futuro.

\subsection{Tradición Literaria}

\subsubsection{Reflexiones filosóficas}

El sentido filosófico de South Park en Arp y Decker (2013) se centra en la paradoja de que, si bien el programa presenta algunas escenas que molestan a los televidentes el autor lo considera como uno de los programas más importantes de la televisión. El problema se sitúa en el "monopolio de la verdad"; la filosofía, como la serie, está en descubrir la verdad para hacer del mundo un mejor lugar para vivir. La diferencia está en que la filosofía es menos impactante que South Park, para hacer pensar a la gente, para fomentar la crítica y generar inestabilidad en las 
creencias y en la realidad del mundo absurdo en que vivimos.

La perspectiva filosófica de Family Guy en Wisnewsky (2007) es una crítica sobre la disfuncionalidad en todos los niveles sociales, ubicándolo entre la tragedia y la comedia. El autor considera que el programa ha sido mal interpretado por cuanto la crítica se queda en la superficialidad de las imágenes y de los diálogos, pero no profundiza precisamente en dichas imágenes y en dichos diálogos. Esta situación ha llevado a que la serie sea el baluarte de esa postmodernidad que no diferencia entre la apariencia y la realidad. La realidad es que estos dibujos animados critican la apariencia de la ética, la estética, la hipocresía, la vida y la trascendencia. Las dos grandes tesis de estos textos se encuentran enfocadas en la cuestión sobre el monopolio de la verdad y la confusión postmoderna de lo real y lo aparente. En esta perspectiva, los estilos de vida se constituyen con una verdad ambivalente y altisonante entre la real apariencia y la aparente realidad.

\subsubsection{Ensayos Sociológicos}

La visión sociológica que presentan los textos de South Park en Thompson (2014), analiza cómo se ha mantenido la serie por cerca de dos décadas con un libreto estúpido, enfermo y depravado. Una serie dirigida a los niños y niñas termina siendo un programa para individuos adultos, a pesar de que una crítica ácida la considera un espectáculo inmaduro. El secreto del éxito del programa es una mezcla intencionada de vidas reales, con tiempos anacrónicos y catástrofes en la pequeña montaña de South Park. Presenta un portafolio de disfuncionalidades personales, individuales y familiares de una sociedad enferma que se resiste a acabar con la humanidad. En Largo, grande y profundo (Hanley, 2013), se analizan los efectos de la serie en la cultura cuando se corren los límites y restricciones propias de las franjas infantiles y juveniles para inferir toda suerte de valoraciones políticas, éticas, religiosas y estéticas. En este espíritu se aborda el texto con las cuestiones morales: el manejo de las células madre, la eutanasia, las drogas en el deporte, el ambiente y las relaciones homosexuales.
En deconstructing South Park (Cogan, 2012) se dice que deconstruir la serie -su desarrollo en sí-, ya es una mala idea. El programa es una mesa redonda para la sátira que se encuentra presidida por Cartman. Es un tratamiento simulado del caos con el doble movimiento de la discapacidad, pero al mismo tiempo de la parodia. No hay nada sagrado sino una pantomima regulada entre dios y el diablo. Es el metadiscurso apocalíptico expresado por las palabras soeces que caricaturiza la política, porque se habla mucha basura; muestra la decadencia humana con una decadencia estética, en la que se profana los estándares de la tradición y los liberaliza, posicionando unas nuevas formas de ser y de actuar. En $E l$ álbum de los recuerdos escolares (Griffin, 2007), de Padre de Familia, se registran los eventos más memorables de su paso escolar. Los aspectos relevantes se esconden en su lado oscuro con las situaciones más degradantes. Es la juvenilización eterna manifestada a través de un joven actual, que seguirá joven mañana y en la vejez. En la perspectiva de los estilos de vida se acentúa la mentalidad infantil y juvenil que se presenta en los individuos de la actualidad, y seguramente del futuro. La infantilización y la juvenilización llevan a que la verdad no sea relativa sino que se relativice. Se desarrollan todo tipo de disfuncionalidades en una sociedad estructuralmente adolescente en la que nada es sagrado, pero es miedosa de cualquier expresión apocalíptica.

\subsubsection{Proposición de estilos de vida}

Anderson (2013) presenta la división social norteamericana en liberales y conservadores. El autor explora que los medios de comunicación norteamericanos no se encuentran inclinados hacia las posiciones liberales sino a la defensa de las posiciones conservadoras por medio de los nuevos medios como Internet, la televisión y la radio. En términos políticos, South Park es una serie republicana. El bien pensante o el manejo de lo políticamente correcto muestra una sociedad enferma que está cansada de que se lo recuerden. El escenario para las nuevas generaciones se visibiliza al decirles a los conservadores que la basura liberal es la nueva dirección correcta, y viceversa. Los 
conservadores son sexistas, racistas, homófobos y los liberales con comunistas, anarquistas y promiscuos. Las lecciones (Simpson, 2014) es un análisis de los capítulos más liberales de la serie, cuya consigna es que los fanáticos del programa ya no se asustan con lo que acontece en el mundo. En el capítulo de los gnomos se argumenta que la libertad de empresa depende del consumo que realicen los clientes de sus productos. El capítulo de la colilla parte de que fumar es malo, pero si las personas a pesar de la advertencia siguen fumando no se les puede restringir. En el capítulo Margaritaville, la enseñanza es que Kyle toma la deuda de toda la ciudad con el fin de que los pobladores restauren la confianza y el poder adquisitivo. Esta maniobra de endeudarse la realizan los gobiernos con el fin de aliviar la deuda de los pobladores.

Las reflexiones de Calahan (2007) están enfocadas a ser guías existenciales de sus seguidores y seguidoras. Se manifiestan como una nueva religión que imparte mandamientos y rituales de vida, que muestra al bebé Stewie Griffin las técnicas para dominar el mundo. La tesis de análisis gira con la ginocracia, cuya máxima se centra en que para dominar el mundo hay que entenderlo. Los resultados se encuentran dentro de uno de aquellos marcos amigables que gustan de la anarquía. Con Griffin (2009) se sigue en la trama de dominar el mundo, pero con un hombre frágil por su pérdida de gusto en la moda, en la música y en la televisión, porque estos aspectos en sí son malos. En esta guía Brian enseña a reinventarse en su doble condición de humano y de perro. Acoge la máxima que dice que no hay criatura mejor preparada sobre cómo ser un hombre que el mejor amigo del ser humano. De La Hoz (2011), en la guía de vida, para lograr el éxito en este mundo, se requiere abordar la existencia de forma absurda. Esta guía se fundamenta en los estilos de vida de los protagonistas de la serie, como son: las reglas de Stewie para dominar el mundo, los principios de Brian para enseñar el arte de la virilidad a los hombres, y los roles infantiles de Lois y Megs para estar en la vanguardia con las nuevas tendencias.

Smith (2007) presenta una guía para disfrutar la navidad. Peter Griffin es el modelo extraordinario para organizarle las vacaciones, especialmente las navideñas, como el mejor momento del año. Independientemente de lo malo o de lo bueno de la lista de vacaciones navideñas, algunas de las sugerencias se identifican plenamente con el descanso de cualquier lado del mundo: dormir hasta tarde y ver televisión todo el día. Los estilos de vida que se construyen no están en la ponderación de posiciones sino en extremar las posiciones en ultraliberales y en ultraconservadores, quienes solamente coinciden en la preservación de su individualidad. Dentro de estos radicalismos se observan unos profundos liberalismos a favor de la economía capitalista, del empresariado empoderado y del hedonismo de los individuos, que es la máxima verdad; en este sentido, también un ultraconservadurismo que no acepta la pluralidad, la diversidad y la inconmensurabilidad. Lo inquietante es que las personas fanáticas de las series de televisión no tienen ningún tipo de posición con relación a la solicitud de orientaciones sobre cómo descansar, en qué trabajar, cómo enfrentar la vida, cómo comportarse frente a la crisis y a los desafíos personales y sociales.

\subsection{Breve historia de South Park y Padre de familia.}

La serie South Park fue creada por Parker y Stone en el año 1991 mientras estudiaban cine en la Universidad de Colorado. El programa se originó con el corto animado: Jesús vs Frosty. Trataba del enfrentamiento entre Frosty, un hombre de nieve, y el niño Jesús. En la pelea Jesús decapitó a Frosty con su aureola. En 1995 los ejecutivos de Fox consideraron gracioso el corto, y contrataron a los creadores para realizar un nuevo corto animado como tarjeta de navidad para enviarla a los amigos y amigas. Este corto trató sobre la confrontación entre Jesús y Papa Noel, quienes terminaron en paz como símbolo navideño. En el mes de agosto de 1997 la serie fue publicitada velozmente por el incipiente internet, ocasionando en los años subsiguientes escándalos en las sociedades estadounidenses, canadienses, y tardíamente en la sociedad latinoamericana. South Park sale en 1998 con su largometraje Longer, bigger and

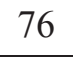

Rev.latinoam.cienc.soc.niñez juv 15 (1): 71-84, 2017 
uncut (Más grande, más largo y sin cortes). El propósito de la película era autocriticarse para enfrentar las opiniones dominantes de los moralistas ultraconservadores. La película pretendía autodesprestigiarse pero obtuvo el efecto contrario con una gran aceptación del público.

La serie Padre de Familia fue creada por Seth MacFarlen en el año 1999 como cortinilla inicial de los juegos realizados en el Superbowl. La trama del programa se desarrollaba en una ciudad ficticia denominada Quahog Rhode Island. Los orígenes de la serie se presentaron con las series animadas The life of Larry $\mathrm{y}$ Larry \& Steve. El personaje central fue el perro, que en la primera temporada se llamaba Peter y en la segunda temporada Brian. En diciembre del año 1998 presentaron un piloto de veinte minutos a los ejecutivos de la Fox, quienes lo vieron exitoso. Tres años después fue cancelado el programa por la productora, por problemas internos. No obstante, las altas ventas de sus productos y de sus accesorios motivaron sacar nuevamente el programa al aire en el año 2004. La serie Padre de familia (Family Guy) tuvo su último contrato con la FOX en el año 2013. La serie ha tenido más de siete temporadas, cada una divididas en cien episodios desde su creación. Este programa proyectó su película directa en DVD denominada: Family Guy presents Stewie Griffin: The Untold Story. Cuyo argumento trataba sobre el niño Stewie, quien busca su yo o identidad aprovechando una distorsión temporal en el futuro para ver su porvenir. Family Guy se posesionó como la marca favorita para el diseño de los juegos en nintendo y en play station.

\subsection{El concepto de South Park y Padre de Familia}

La trama de la serie de South Park se presenta en un contexto cómico sobre la vivencia de cuatro niños que viven en un pequeño pueblo ficticio del mismo nombre. El programa realiza una crítica con un lenguaje fuerte mostrando a los niños racionales e inteligentes y a las personas adultas irracionales e idiotas. Los personajes en el programa cumplen una función crítica frente a los líderes y frente a las instituciones sociales como la escuela, la iglesia y los estamentos gubernamentales. En los libretos se critica los problemas coyunturales en materia política, económica y religiosa. Por ejemplo: la invasión de EE.UU. a Irak y a Afganistán, la valoración superior de la cultura anglosajona con respecto a la cultura latinoamericana, la visita del Papá a South Park para criticar las visitas del Pontífice a Canadá y a EE.UU. La serie ha sido vetada por los presidentes Putin (Rusia) y Calderón (México).

El nudo de la serie de Padre de Familia se encuadra en una familia que vive en una ciudad ficticia de Montreal; en este contexto se critica a las familias anglófonas, creando unas situaciones provocadoras con respecto a las buenas costumbres, a la incitación e imitación al crimen, a la apología de la drogadicción y al sexo "desviado". La crudeza del programa ha llevado a los productores a cancelar la serie, pero al mismo tiempo a revivirla gracias a los miles de seguidores y seguidoras que han realizado toda suerte de acciones como: recolección de firmas, envío masivo de correos, manifestaciones y boicoteos a la productora, entre otras actividades. Los detractores consideran el programa una comedia sucia que busca entretener con la sátira y el escándalo familiar. Los defensores argumentan que la serie es una mezcla novedosa de crítica y de humor inteligente para cuestionar situaciones crudas sobre el establecimiento de lo establecido. En algunos capítulos de las series de South Park y de los Simpsons se ha criticado a Padre de Familia por ser una serie que utiliza un lenguaje inapropiado, la desnudez animada y el contenido violento.

\subsection{Personajes de South Park y Padre de Familia}

Los personajes centrales de South Park son los niños: Kenny, Stan, Cartman y Kyle. Ellos viven en un ambiente de pobreza, mediocridad e inferioridad social, escenarios que posibilitan la función de la crítica, la sátira, la ironía y el sarcasmo. Las características que Stan presenta en la serie son la de un niño adulto, que comunica serenidad y asume el rol de líder, que jalona e inspira a sus amigos. Su mayor preocupación 
es por preservar su buena imagen viviendo de las apariencias familiares. La particularidad de Kyle está en su origen judío, que le causa diversos conflictos por las manifestaciones antisemitas que se presentan en el programa. De los cuatro es el que más se cuestiona, y su mayor preocupación está en establecer la verdad. La singularidad de Cartman se manifiesta por sus actitudes antisociales: se ha declarado xenófobo y desprecia a los judíos, es complaciente con sus amigos pero a las personas adultas las considera idiotas; su mesianismo lo ha llevado a no interesarle el dolor ajeno sino sólo su bienestar. La peculiaridad de Kenny es que procede de la pobreza, permanece en silencio y al final del capítulo lo matan, pero vuelve aparecer en el siguiente programa. A lo largo de las temporadas lo han dejado de matar y habla un poco, aunque no se le entiende.

Los protagonistas centrales de Padre de Familia son: Peter (el padre), Lois Griffin (la madre), y sus hijos Meg, Chris y Stewe Griffin. Ellos están acompañados por la figura de un perro antropomórfico llamado Brian Griffin. Esta familia se caracteriza por vivir situaciones inverosímiles queconel recurso de lairreverencia critican la actual disfuncionalidad social. Peter, el padre de los Griffin, es un obrero exitoso de una industria tecnológica; por su retardo mental actúa de forma ingenua, torpe e incompetente. $\mathrm{Su}$ personalidad es impulsiva y es celoso con su esposa por aquellos que se acercan a ella. Se burla de su hija Meg, desorienta a Chris, pero conversa amablemente con Stewie. Lois, la madre de los Griffin, se ha transformado significativamente de una dama de la alta sociedad que vivía con un esposo tonto y unos hijos malcriados, en las primeras temporadas, a las últimas temporadas en las que desvela su lado oscuro presentándose promiscua, bisexual, sadomasoquista, ludópata y drogadicta. $\mathrm{Meg}$, la hija mayor de los Griffin, se considera gorda y fea, no se siente acogida por su familia y acepta cualquier propuesta para no contrariar a sus amigas. En las últimas temporadas es ignorada por la familia; esta situación la ha vuelto psicótica y bipolar, situación que la ha llevado a secuestrar, asesinar y tener relaciones zoofílicas con Brian.

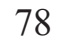

Chris, el hijo medio de los Griffin, despliega su talento artístico en la pintura y la música; tiene como modelo a su padre, y de ahí su poco sentido común. Muestra indicios de esquizofrenia cuando confronta a sus amigos psicóticos con los imaginarios. A pesar de ello es un adolescente educado y amable. Stewie es el bebé lactante de los Griffin; su inteligencia de adulto le permite manejar la ingeniería física y la mecánica para hacer prototipos científicos. Estas cualidades están acompañadas por su lado oscuro agresivo que lo lleva a cometer delitos criminales como el robo y el asesinato. Su intención es dominar el mundo, pero necesita matar a su madre aunque nunca logra este objetivo. Brian es la mascota de los Griffin: un perro antropomorfo que camina con las patas traseras, en tanto las patas delanteras le sirven de brazos. Habla y razona más que los integrantes de la familia. Su oficio es el de escritor. Tiene los comportamientos humanos del gusto por la cultura y por las posiciones liberales. $\mathrm{Su}$ comportamiento canino se manifiesta en recoger la pelota que le tiran.

\subsection{Estilos de vida de South Park y Padre de Familia}

Los estilos de vida que se dejan entrever con los personajes de la serie de South Park son los siguientes:

El niño Stan, a pesar de su liderazgo y su madurez, presenta un estilo de vida en el que se preocupa por las apariencias, por el excesivo cuidado de su imagen, y por el modelaje del estereotipo de la efigie de la exterioridad y la superficialidad. El niño judío Kyle representa el estilo de vida de la maleabilidad en el que no tiene convicciones fijas sino que actúa conforme a la variabilidad de las circunstancias, de las opiniones y de su bienestar particular. El niño gordo Cartman manifiesta dos características en su estilo de vida: su mesianismo y su narcisismo frente a sus amigos. Su mesianismo se expresa por considerarse como el hermano mayor salvador de los demás. Su narcisismo se manifiesta por sus actitudes infantiles como la autoadoración. El niño silencioso Kenny representa el estilo de vida enigmático y misterioso caracterizado por la ausencia 
social, su ocultamiento frente a la comunidad, su anonimato frente a la fama y su bajo perfil frente al control que ejercen sus amigos y la sociedad. Su visibilidad se expresa cuando lo aniquilan.

Los siguientes son los estilos de vida que se destacan en los personajes de la serie Padre de familia:

La personalidad compleja y complicada de Peter el papá, representa el estilo de vida que se construye a partir de la azarosidad; a pesar de sus limitaciones cognitivas y de sus idioteces tiene un éxito desmedido en la vida personal y laboral. La personalidad disonante de Lois, la mamá, expresa un estilo de vida camaleónico; su actuación está de acuerdo con sus paranoias cotidianas. La mutación comportamental se manifiesta cuando sospecha de las acciones benevolentes reaccionado perversamente. La hija mayor, $\mathrm{Meg}$, manifiesta el estilo de vida del reconocimiento y de la pusilanimidad. $\mathrm{Su}$ comportamiento positivo o negativo depende de si es reconocida por sus amigas o amigos. $\mathrm{Su}$ actitud turbia se manifiesta cuando tiene que tomar decisiones límite o importantes, pero vacila porque no tiene juicios claros. El segundo hijo, llamado Chris, muestra un estilo de vida denominado plegable, por su flexibilidad frente a las decisiones. Es una personalidad que se deja enrollar o desmontar por las circunstancias sin tener en cuenta ningún criterio. El bebé Stewie revela un estilo de vida llamado de desacoplamiento cruzado, por cuanto no hay una relación coherente entre los parámetros cognitivos y los estándares cronológicos. En este caso, la precocidad intelectual le trae una desadaptación con los demás para ver la vida con realismo.

\section{Estilos de vida}

Los estilos de vida que se presentan en estas dos series, se infieren en dos escenarios de reflexión: el primero parte de los personajes que caracterizan los estilos de vida tradicionales de la sociedad; el segundo está relacionado con aquellos personajes cuyas características personalesmodelanlosestilos devidaemergentes de los futuros ciudadanos y ciudadanas. En el primer escenario se encuentran los siguientes estilos de vida: el de quien vela por el cuidado de la imagen (Stan), el de quien se autoadora o el narciso, el de quien se revela como el mesías o sufre el síndrome mesiánico (Cartman), el de quien actúa camaleónicamente (Lois) y el de quien asume la vida con la elasticidad de sus pliegues vitales (Chris). En el segundo escenario emergen los siguientes estilos de vida: el de quien actúa de forma dúctil y maleable (Kyle), el de quien se mueve subrepticiamente en la sociedad (Kenny), el oportunista del flujo azaroso (Peter), el pusilánime que no tiene posiciones propias (Meg) y el consciente desacoplado cruzado (Stewie).

\subsection{Estilos de vida tradicionales}

El estilo de vida del cuidado de la imagen (Stan) proviene de los medios de comunicación, específicamente de los audiovisuales de la televisión y del cine. Estas mediaciones comunicativas han ido introduciendo la noción de imagen en la cotidianidad humana en el siglo XX, y se han profundizado en la actualidad del presente siglo. La imagen que se ha desarrollado es la de aquella axiología en la que se ha penetrado por etapas: La imagen de la ética de las noticias según la cual se requiere de la información para tomar decisiones y tener el poder. La imagen de la estética en la que se modela las formas de vivir en la figura, el color y los contornos, comunicando nuevos gustos, bellezas y divinidades. Finalmente, la imagen de la política en la que se promueve estereotipos que conducen a los conceptos de la fama, la apariencia, la exterioridad, la epidermis y la superficialidad.

El estilo de vida que comunica el narcisismo (Cartman) procede de una cultura de la imagen que promueve la exagerada forma de verse a sí mismo. Este mirarse a sí mismo provoca las diferentes visiones del egocentrismo contemporáneo. La visión del egocentrismo en la ética se transforma en un literal egoísmo, que se expresa en las diferentes conductas de autoaceptación, autocomplacencia, autoconfirmación y autoconsideración, en donde los demás tienen la responsabilidad y la culpabilidad del deterioro del ego. La visión del egocentrismo en lo estético se refiere a la 
incorporación de la diversidad de gustos para sobredimensionar el ego, sin importar las posibilidades de hacerlas realidad. Con respecto a la visión del egocentrismo en lo político, ésta se plantea en términos de tolerancia hacia los demás cuyo criterio central está en valorar la conveniencia o inconveniencia personal.

El estilo de vida mesiánico (Cartman) se visibiliza en el autonombramiento del individuo como hermano mayor de una sociedad, de una comunidad o de un grupo de personas. Se confunde al hermano mayor con el potencial líder que jalona e inspira algún proyecto. El mesías, en una mirada ética, pretende ser el elegido para promocionar la sociedad, pero en sus actuaciones se desvela que su fin es autopromocionarse camuflado con el servicio social. Este mesianismo, desde una óptica estética, se plantea en términos de sublimidad, porque sus acciones en sí son tan extraordinarias que se requiere aplaudirlas, alabarlas, reconocerlas y reportarlas para la posteridad. Con respecto a lo político, el mesías o el hermano mayor personifica la autoridad y el poder mediante la personificación de sí mismo, exteriorizándolas con los medios de la ley, la norma y la regla.

El estilo de vida del síndrome camaleónico (Lois) se caracteriza por las permanentes metamorfosis que sufre cotidianamente el individuo con respecto a las situaciones o a los pliegues conflictivos que alteran el ego, la imagen o el mesianismo. En esta perspectiva, en la reflexión ética se presenta un divorcio entre lo que se piensa con relación a lo que se hace. Hay una separación intencionada entre los discursos y los comportamientos. En cuanto a la reflexión estética, la prelación se encuentra en la formalidad de la apariencia con relación al fondo de las esencias. La notoriedad del gusto del individuo estriba en la fachada por encima de la realidad. Con respecto a la reflexión política, la única posición del camaleón es sacar la máxima utilidad posible para beneficiar su zona de confort, que la tiene bien determinada para fortalecer la individualidad.

\subsection{Estilos de vida emergentes}

Las personas que actúan con el estilo de vida de la ductilidad maleable (Kyle) se caracterizan por presentar actitudes de acomodación y de adaptabilidad. La acomodación se visibiliza en el individuo con la maximización de la zona de confort, mediante la prolongación y permanencia de su bienestar particular. La adaptación es un efecto defensivo de la acomodación, que se manifiesta en el individuo esforzándose en preservar su bienestar con las actitudes de la maleabilidad, de la docilidad y de la condescendencia. El cuadro axiológico de los individuos de la ductilidad le apuesta a la discontinuidad ética, estética y política de los paradigmas de la maleabilidad de lo bueno que tiene lo malo, de lo bello que tiene lo feo, de los fines que tienen los medios, y así recíprocamente. La ductilidad se presenta en los futuros ciudadanos y ciudadanas como figurillas denominadas marionetas o títeres.

Las personas que actúan con el estilo de vida de la subrepticidad social (Kenny) se identifican por su intencionalidad de camuflarse y de vivir en el anonimato. El camuflaje se manifiesta en los individuos de la actualidad, en la necesidad de ocultarse, encubrirse o disfrazarse porque, gracias a la tecnología, estos sujetos se sienten rastreados por el celular, por las cámaras y por los dispositivos de control. El anonimato se expresa actualmente en los individuos mediante los mecanismos de defensa que buscan detener el acoso tecnológico $\mathrm{y}$ virtual que socializan las individualidades con los conceptos de usuario, correo o perfil. El marco axiológico de los individuos de la subrepticidad le apuesta a las subsuelidades de la ética, de la estética y de la política, con el paradigma subterráneo de abordar el asunto ético con la doble moral, de apreciar lo estético en la conformidad y la deformidad subjetiva y de participar políticamente con la indiferencia activa. Lo subrepticio se presenta en los futuros ciudadanos y ciudadanas llamados invisibles, denominados de la invisibilidad.

Las personas que actúan con el estilo de vida de la fugacidad azarosa (Peter) se proyectan por vivir con gran esmero el instante y con gran densidad el momento. El instante se presenta en los individuos que quieren disfrutar cada segundo posible sin ninguna preocupación de un futuro a mediano o largo 
plazo. El momento se expresa en los individuos que economizan sus acciones para aprovechar la coyuntura, la oportunidad y la ocasión para enaltecer su individualidad con el éxito. Estas personas buscan la notoriedad en la fugacidad del azar. La base axiológica de estos individuos se plantea en la aleatoriedad en los términos de la ética, la estética y la política. Lo bueno es aquello que contribuye al crecimiento del ego. Lo bello es aquello que enaltece la imagen. El bien general es la mutación de los fines hacia aquellos medios que fomentan el bien particular. Lo azaroso se presenta en los futuros ciudadanos de la inminencia y de la inmediatez.

Las personas que actúan con el estilo de vida de la pusilanimidad (Meg) se manifiestan como aquellos individuos que viven sin ningún tipo de criterio o de juicio estable, revelándose su condición mediante la fobia y la ilusión. La fobia es entendida como aquella inclinación de los individuos a tener aversión para enfrentar la vida con realismo, porque lo hace de forma ficticia o virtual. La ilusión es comprendida como aquellos deseos de los individuos por tener anhelos que se transforman en espejismos quiméricos irrealizables. El planteamiento axiológico de estos individuos se presenta en la fragmentación ética, estética y política. El individuo aborda las acciones buenas desintegrándolas en acciones molestas. Se acoge lo bello fraccionándolas con gestos de mal gusto. En lo político se fracturan las normas, las leyes y las orientaciones hacia la conveniencia particular. La pusilanimidad se presenta en los futuros ciudadanos y ciudadanas de la ceguedad y la alucinación.

Las personas que actúan con el estilo de vida del desacoplamiento cruzado (Stewie) se expresan en aquellos individuos que viven entre la precocidad y la agracidad. La precocidad se muestra, por un lado, en aquellos sujetos adolescentes que asumen roles y decisiones propios de las personas adultas. La consecuencia de esta precocidad ha traído a los individuos, procesos de involución manifestados en los sujetos adultos adolescentes o personas adultas infantiles. La agracidad de los individuos está relacionada con la anterior precocidad. La desazón es propia de las personas adolescentes adultas que se agobian por el peso de las responsabilidades que adquieren. La amargura es propia de los sujetos adultos infantiles porque no vivieron las etapas de la infancia, y en compensación incorporan un estilo de vida correspondiente a una adolescencia infinita. La axiología que se visibiliza está planteada en la encrucijada de la ambigüedad ética, en la metamorfosis estética y en una desadaptación sociopolítica.

\subsection{La promoción de la hiper- individualidad}

En este breve análisis de las dos series de televisión de South Park y Padre de Familia, es coincidente que ambos programas promueven activamente la hiper individualidad. La individualidad en la premodernidad se planteaba en términos objetuales relacionados con la naturaleza o con la divinidad. La individualidad en la modernidad se situaba en la subjetividad racional que fomentaba los derechos de la libertad, la fraternidad y la igualdad, junto con los deberes de la corresponsabilidad con los demás. La individualidad de la postmodernidad contemporánea se encuentra modelada por la racionalidad de los medios de comunicación y de las tecnologías de la información. Esta hiper-individualidad se encuentra muy bien graficada con Brian, el perro antropomorfo, que es la mascota de la familia de los Griffin, y que simboliza la humanización de los animales que se comportan como individuaciones, pero igualmente representa la animalización de los humanos que prefieren tener al lado a las mascotas que a sus propios congéneres.

Esta hiperindividualidad se presenta en términos de complejidad proveniente del Siglo $\mathrm{XX}$, y se ha prolongado hasta la actualidad. La complejidad es tejida por las nuevas dimensiones que se han profundizado en la individualidad del humano contemporáneo. Estas dimensiones emergentes en la ética se visibilizan en los siguientes estilos de vida: las actuaciones camaleónicas, las actitudes dúctiles maleables y los comportamientos pusilánimes. Las dimensiones nacientes en la estética se manifiestan en los siguientes estilos de vida: los meticulosos de la imagen, los fugaces azarosos y los desacoplados cruzados. Finalmente, 
las dimensiones florecientes de la política se presentan con los siguientes estilos de vida: el narcisismo egocéntrico social, el mesías o hermano mayor controlador, y el ausente subrepticio social.

Estos ciudadanos y ciudadanas hiper individualizados van estructurando unas nuevas ciudadanías y reinventando otras en los estilos de vida de los individuos caracterizados por la vipmanía, con las propiedades de una vida a la medida, con posibilidades de vivirla libremente, marcadas por el confort y por el placer; este hedonismo intencionado se encuentra comunicado por la virtualización y la simulación. Estas ciudadanías podrían denominarse de la siguiente forma: la ciudadanía de la mutación (camaleón), la ciudadanía de la flexibilidad (ductilidad), la ciudadanía de la sensibilidad (pusilanimidad), la ciudadanía totémica (imagen), la ciudadanía de la aleatoriedad (fugacidad azarosa) y la ciudadanía de la ausencia (subrepticidad).

\section{Conclusiones}

South Park y Padre de Familia son pequeñas muestras de las fuertes influencias que tienen los medios de comunicación y las nuevas tecnologías de la información y de la comunicación en la constitución de los proyectos y en el modelaje de los estilos de vida. En los últimos años ha habido un entrecruzamiento de la premodernidad, de la modernidad y de la forma sustancial de la postmodernidad en la configuración de los estilos de vida. La familia como institución premoderna y la escuela ilustradora como institución de la modernidad, configuran y preparan los proyectos de vida para asumir acríticamente los estilos de vida que proponen los mass media y las nuevas tecnologías. Estos tres escenarios ofrecen a los individuos, como política pública: mayor libertad, mejor equidad, óptima calidad de vida y máximo bienestar particular. La población infantil, juvenil y los individuos jóvenes adultos, han interiorizado estos conceptos provenientes de su círculo familiar, escolar y mass mediáticotecnológico, expresándolos en los estilos de vida que he inferido en este trabajo.

Los estilos de vida actuales han traído de suyo la reconfiguración de identidades tradicionales, emergentes y vanguardistas; a continuación precisaré cada una de ellas:

La identidad de la combinación sincretista se manifiesta en los estilos de vida de la ductilidad y de la maleabilidad. Estos individuos gustan de las zonas de confort; por ello se comportan de forma flexible, elástica y moldeable, para permanecer siempre adaptados y acomodados en su seguridad. Actualmente se manifiestan en los ciudadanos y ciudadanas denominados títeres o marionetas. La identidad de la combinación ecléctica se manifiesta en los estilos de vida de la pusilanimidad. Estos individuos viven sin ningún tipo de juicio o criterio; sus decisiones se realizan a partir de las fobias y las filias. Sus acciones se encuentran jalonadas por el miedo y por el culto de las inclinaciones; son los ciudadanos y ciudadanas que se forjan en la alucinación, la ceguedad y la opacidad de las circunstancias.

La identidad de la borrosidad se presenta en el conjunto de estilos de vida caracterizados por la hiperindividualidad en el justo a tiempo, en el todo a la medida, en el hedonismo seguro $\mathrm{y}$ en la virtualización vital. Sus acciones se encuentran direccionadas a buscar la confusión para poder incorporarse. Se van estructurando los ciudadanos y ciudadanas mutantes, dúctiles, pusilánimes, totémicos, subrepticios y aleatorios. La identidad de la ambivalencia se manifiesta en los estilos de vida representados por el cuidado de la imagen. Sus acciones se encuentran monitoreadas por el asesor, y por la presión laboral y social. Se van configurando las ciudadanías de la fama, de la apariencia, de la epidermis, de la exterioridad y de la superficialidad.

La identidad del desacoplamiento generacional se muestra en los estilos de vida del narcicismo, del egocentrismo, de la precocidad y de la dilación. Es el individuo narcisista que de forma consciente promueve su imagen, sus logros y sus éxitos. El egocentrista que ubica su yo en el centro de todas las circunstancias posibles. De la precocidad de la ginocracia y de la dilación de la androcracia están surgiendo fenómenos como la adultización de la gente joven y la infantilización de las personas adultas. La identidad de la disfuncionalidad individual se 
exhibe en los estilos de vida cuyas actuaciones producen las consecuencias contrarias al funcionamiento regular, impactando el sistema social. En la actualidad, paradójicamente, lo sagrado se ha erosionado pero lo apocalíptico se ha reinventado. El misterio de lo sagrado se ha desvanecido junto con sus ritualidades, que se han transformado en otro espectáculo más. El apocalipsis, en cambio, se ha estructurado con el fin del mundo, el fin de la naturaleza y el fin de los seres humanos. Se gestan nuevas creencias, pero paralelamente nuevos escepticismos. Se cree ciegamente en la Internet, pero no se cree en la humanidad, constituyéndose unas nuevas religiones.

La identidad del individualismo ponderado ante las posiciones extremas de la derecha y de la izquierda en términos políticos se ha prolongado a las acciones morales. Por ello los estilos de vida no tienen posiciones claras sino sinuosas conforme con las circunstancias. Ante la incapacidad de decidir y de tomar posiciones sólidas, son muy accesibles frente a cualquier recomendación o guía de vida frívola, frente a los diez mandamientos de South Park, Padre de familia o los Simpsons. La identidad de la individualidad redentora se presenta en los estilos de vida mesiánicos en las modalidades de hermano mayor, el sensei social o el mesías político o económico. Sus actuaciones son de autorrepresentación, de autopromoción y de autorreconocimiento como líder y cabeza de sociedad. Estos ciudadanos y ciudadanas confunden fácilmente el bienestar particular con el bienestar general.

La identidad de la individualidad metamórfica se manifiesta en los estilos de vida camaleónicos, que se caracterizan por su transformación personal, familiar, social y cultural. Las acciones reiteradas radican en que no hay conciencia ni coherencia entre lo que se piensa, lo que se siente y lo que se hace. De estos comportamientos emergen las ciudadanías de los discursos, de las emocionalidades y de las indiferencias. Es la identidad de la presencialidad ausente que se presenta en los estilos de vida silenciosos, anónimos y ligados a las tecnologías. Sus actuaciones subrepticias son sus únicas participaciones y sus camuflajes sofisticados son sus credenciales. El anonimato intencionado es su mecanismo de proyección presencial que utiliza mediante Facebook,
Twitter y con el celular. Estos ciudadanos y ciudadanas tienen incapacidad de enfrentar de forma realista la vida, y lo hacen con dispositivos. La identidad de la aleatoriedad se visibiliza con los estilos de vida de la fugacidad azarosa que gustan del momento, del instante y de la ocasión. Sus actuaciones están en el corto plazo y no tienen un plan hacia el largo plazo. Son ciudadanos y ciudadanas que trabajan por un mes, y con el dinero ganado viajan fuera del país. En el país al que llegan trabajan por otro mes, y así sucesivamente. Se llaman los hippies tardomodernos.

La tendencia ética, estética y política que surge de este análisis se podría denominar de la distorsión coordinada y organizada. En lo ético se erosionan las visiones tradicionales de la bondad y de la maldad, pero se diluyen y se regulan a partir de las nuevas orientaciones morales promovidas por los mass media. Los medios de comunicación alertan, pero al mismo tiempo promueven la intolerancia para lograr las respectivas teleaudiencias. En lo estético se ha deteriorado la noción subjetiva de lo bello y de lo feo por el enfoque orientador de las tecnologías de la información, que determinan qué es lo conforme y lo deforme para que los sujetos puedan consumir los nuevos dispositivos. En lo político, se han destruido los límites entre en el bien particular y el bien general, por el permanente bombardeo de las nuevas tecnologías y de los medios de comunicación, pues hoy lo importante es la individualidad y las individualidades de los sujetos, ignorando la colectividad participativa en deberes y derechos.

\section{Lista de referencias}

Anderson, B. C. (2013). South Park Conservatives. The revolt against liberal media bias. Washington: Regnery Publishing.

Arp, R. \& Decker, K. S. (2013). The ultimate South Park and philosophy. Respect my philosophah. Oxford: Blawell Philosophy and Culture Series.

Baiget, T. (2015). Anuario ThinkEPI2015. Análisis de tendencias de información y documentación. Barcelona: EPI SCP.

Calahan, S. (2007). Padre de Familia. Barcelona: Astiberri. 
Cogan, B. (2012). Deconstructing South Park. Critical Examinations of Animated Transgresstion. New York: Lexington Books.

De La Hoz, C. (2011). Family Guy Gide to Life. Philadelphia: Running Press.

Espinosa, F. J. (2011). La igualdad de género en la evaluación de la ayuda del desarrollo. Madrid: Universidad Complutense de Madrid.

González, A. \& Rodríguez, R. (2014). Caos digitalymedios comunes. Transformaciones de la comunicación social en el Siglo XXI. Madrid: Dikinson.

Griffin, B. (2009). Padre de Familia No 2. Barcelona: Astiberri.

Griffin, S. (2007). Family Guy: The Stewie Griffin School of Hard Knocks Grad Pad: A personalized, Ultraconfidential Yearbook. New York: Harper Collins.

Hanley, R. (2013). South Park and Philosophy. Bigger, Longer and Penetrating. Chicago: Popular Culture and Philosophy.

Jarvis, J. (2014). El fin de los medios de comunicación de masas. Barcelona: Gestión 2000.

López, J. P. (2004). Mi proyecto de vida. México D. F.: Panorama.

Monbourquette, J. (2000). A cada cual su misión. Descubrir el proyecto de vida. Santander: Sal Terrae.

Pardo, I. (2005). Jóvenes construyendo su proyecto de vida. Bogotá, D. C.: Magisterio.

Penas, S. (2008). Aproximación a los valores y estilos de vida de los jóvenes de 13 y 14 años de la Provincia de Coruña. Coruña: Santiago de Compostella.

Rodríguez, J. A. (2014). Aproximación de un modelo teórico de participación social que ofrezca la calidad de vida desde el contexto de la educación venezolana. Córdoba: Universidad de Córdoba.

Simpson, B. (2014). The libertatian lesson of South Park: An analysis of libertarianism in South Park. Santa Fe: Small Town Press.

Smith, D. (2007). Family Guy: Peter Griffin's Guide to the holiday. New York: Harper Collins.
Thompson, D. (2014). South Park. FAQ. All that's left to know about the who, what, where, when and... of American favorite mountain town. Milwakee: Montclaire.

Unesco (2014). Indicadores de género para medios de comunicación. París: Sector de la Comunicación y de la Información.

Wisnewsky, J. (2007). Family Guy and Philosophy. Nueva York: Wiley-Blackwell. 